\title{
Transplant immuno-diagnostics: crossmatch and antigen detection
}

\author{
Andrew M. South ${ }^{1}$ • Paul C. Grimm ${ }^{1}$ \\ Received: 27 April 2015 /Revised: 1 June 2015 / Accepted: 8 June 2015 / Published online: 3 July 2015 \\ (C) IPNA 2015
}

\begin{abstract}
Identifying and monitoring donor-directed anti-human leukocyte antigen antibodies are a rapidly evolving area of solid organ transplantation. Donor-specific antibodies dictate pre-transplant donor choice and donor-recipient matching and underlie much acute and chronic allograft rejection and loss. The evolution of available technology has driven this progress. Early, labor-intensive, whole-cell assays based on complement-dependent cytotoxicity suffered from poor sensitivity and specificity, technical challenges and lack of precision. Sequential improvement in assay performance included anti-human immunoglobulin-enhanced, complementdependent cytotoxicity techniques followed by cell-based flow cytometry. However, variable specificity and sensitivity inherent in cell-based testing continued to limit flow cytometry. The introduction of solid-phase assays led to a second revolution in histocompatibility testing with the use of purified antigens bound to artificial surfaces rather than whole cells. These techniques augmented sensitivity and specificity to detect even low-titer antibodies to previously undetected antigens. Identification of complement-activating antibodies is being introduced, but current technology is in the developmental stage. While the detection of alloantibodies has improved dramatically, our comprehension of their importance remains imperfect. Variability in methodology and a lack of standardization limits the clinical application of these tests. In spite of the hurdles that remain, antibody-mediated rejection has become a key target to improve graft survival.
\end{abstract}

Andrew M. South

andrew09@stanford.edu

1 Division of Pediatric Nephrology, Stanford University, 300 Pasteur Drive, Room G-306, Palo Alto, CA 94305, USA
Keywords Donor-specific antibody · C1q · Histocompatibility · Complement dependent cytotoxicity · Virtual crossmatch

\section{Introduction}

Patel and Terasaki's recognition, in 1969, of the association between hyperacute renal transplant rejection and recipient alloantibody to donor antigens marked a sea change in our knowledge of transplant immunology and, in turn, outcomes of clinical organ transplantation [1]. This landmark study led to the routine use of the prospective crossmatch in clinical transplantation. Subsequent studies established that prospective identification of antibodies of public human leukocyte antigen (HLA)-shared epitopes could predict crossmatch outcome [2]. This led to the virtual crossmatch and the ability to prioritize highly sensitized patients for a crossmatchcompatible donor, increasing the number of successful transplants for this relatively disenfranchised population. The persistence of negative crossmatches but high rates of graft loss in sensitized, high-risk patients led to the development of more sensitive techniques [3, 4]. While there have been significant advances in detecting and predicting lower levels of donorspecific anti-HLA antibodies (DSAs), our ability to interpret their clinical significance has not kept up with the availability of the data.

\section{Biology}

Human leukocyte antigen proteins are critical to the body's defense against foreign material by facilitating the recognition and differentiation of self from foreign proteins. Cell-surface HLA proteins bind exported intracellular peptides onto an 
outwardly facing grove in the HLA molecule. Immune cells determine self from foreign peptides based on interactions between the individual HLA molecule and its bound antigen with the T-cell receptor (TCR) of an opposing immune cell, such as a $\mathrm{T}$ lymphocyte. The rapid recruitment and binding of multiple co-receptor proteins expressed on both sides of the "immunological synapse" amplifies the TCR-HLA molecule interaction and subsequent intracellular response. The aggregate of dozens of signals passing in both directions leads to a decision by the effector cell to either initiate an immune response or to tolerate or ignore this event. This cellular communication is critical in transplantation medicine. Immunosuppressive medications are used in clinical medicine in an attempt to interfere with this process in order to prevent immune system identification, antibody formation, cellular destruction and rejection.

The major histocompatibility complex (MHC), a collection of over 200 genes on chromosome $6 p$, encodes the MHC proteins, which in humans are also referred to as HLA proteins. There are three main groups of MHC genes: class I, class II and class III. Class I and class II MHC genes encode the HLA proteins of interest in transplantation (Fig. 1). Relevant class I genes include HLA-A, HLA-B and HLA-C. Class I MHC molecules have two polypeptide chains: a long $\alpha$ chain and a short invariant chain of $\beta 2$ microglobulin. The variability of class I HLA proteins is predominantly in the peptide-binding region, namely, the $\alpha_{1}$ and $\alpha_{2}$ domains. The proteins produced by these genes are expressed on the surface of virtually every nucleated cell in the human body. Class I HLA molecules bind endogenous cytosolic peptides and are recognized by cytotoxic $\mathrm{T}$ cells.

There are six primary MHC class II genes: HLA-DPA1, HLA-DPB1, HLA-DQA1, HLA-DQB1, HLA-DRA and HLA-DRB1. Class II molecules also consist of two polypeptide chains, namely, $\alpha$ and $\beta$, of essentially equal length. Class II HLA variability is concentrated in the peptide-binding region composed of the $\alpha_{1}$ and $\beta_{1}$ domains. HLA proteins produced by these genes are expressed almost exclusively on antigen-presenting cells (APC) under steady-state conditions. HLA class II expression is commonly induced on nonprofessional APC under conditions of inflammation or tissue injury. In contrast to class I, class II HLA molecules usually bind peptides of exogenous or extracellular origin that have been endocytosed from the environment of the APC. The nascent class II molecule is protected from acquiring peptides of internal origin by a blocking peptide (class II-associated invariant chain peptide) that sits in the binding groove until the nascent class II HLA molecule enters a phagolysosome. At that point, the binding peptide is removed, the HLA molecule is loaded with exogenous peptide and the completed antigen presentation unit is shuttled to the cell surface where it is generally recognized by helper $\mathrm{T}$ cells (Th) [5].
HLA genes have numerous variations, or alleles, and each HLA protein has two alleles, leading to extremely diverse HLA expression. The high degree of HLA genetic polymorphisms allows the immune system to recognize an incredibly diverse spectrum of peptides. This diversity facilitates the species' ability to respond to a broad range of pathogens. However, these genetic polymorphisms make transplant immunology complex. APCs from the transplanted organ may primarily interact with host Th cells to trigger an immune response to the intact HLA molecule (direct allorecognition). Recipient APCs may also take up HLA molecules from donor cells, process them into small amino acid fragments and present the fragments to recipient Th cells in the antigen-binding groove of self-HLA molecules (indirect allorecognition). In this way, HLA molecules may induce immune responses to natural conformations of the molecule and to post-processing fragments. High HLA allelic variability makes the detection and interpretation of DSAs difficult. New technology is beginning to address these polymorphisms and improve our knowledge of transplant immunology.

Antibody-mediated activation of the complement cascade, a crucial part of the effector arm of the adaptive immune response, is the hallmark of antibody-mediated rejection, as well as the basis for HLA testing. Alloantibodies against HLA antigens activate the classical complement pathway by binding $\mathrm{Clq}$, thereby initiating formation of the membrane attack complex (MAC), leading to target cell lysis and death (Fig. 2). Activation of the complement pathway also recruits immune cells, amplifying inflammation and tissue injury. Histocompatibility technology has evolved from directly detecting anti-HLA antibody-mediated cytotoxicity on live cells to isolating the complement-activating effect of these antibodies at a chemical level without the necessity of actual cells.

\section{Evolution of testing}

\section{Direct complement-dependent cytotoxicity}

The initial antibody-detection methods were based on complement-dependent cytotoxicity (CDC), which identifies preformed complement-fixing antibodies [6]. The CDC crossmatch uses a 96-well plate where tiny volumes of reagents in the order of 1-6 $\mu$ l react with each other suspended in a drop of mineral oil. Reactants including cells, patient serum and complement are sequentially added to each well. In a positive reaction, complement-fixing antibodies coat the cell surface, activating the complement cascade, culminating in the MAC perforating the cell membrane. The uptake of DNA dye, which healthy cells normally exclude, signals loss of cell membrane integrity because it enters dying cells and binds DNA. A technologist then qualitatively estimates the percentage of cell death using a microscope. There are many potential 
Fig. 1 Major histocompatibility complex $(M H C)$ genes and human leukocyte antigen $(H L A)$ proteins

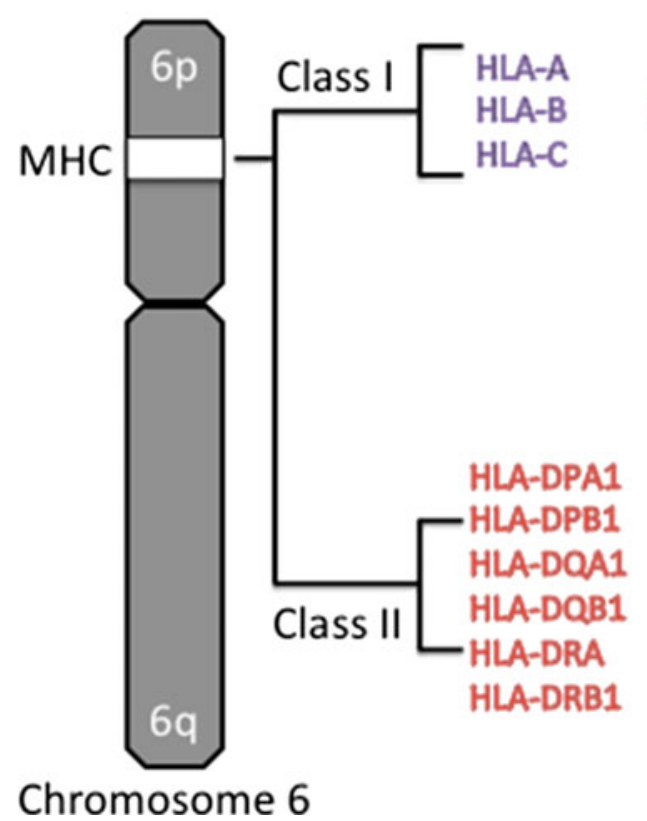

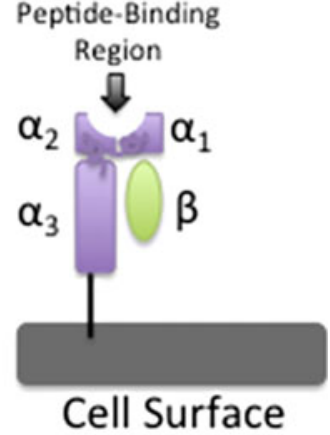

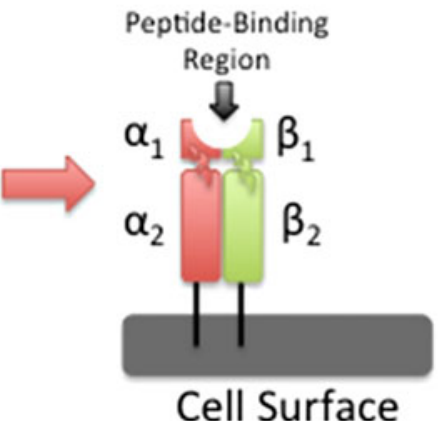

sources of error in this multistep process. For example, substantial background cell death, which frequently occurred when injured target cells were drawn from a critically ill potential deceased donor, often led to difficulty in detecting the presence of additional cell death caused by the patient serum in question.

These initial direct CDC assays, while revolutionary, have numerous limitations. They are non-specific and are frequently confounded by cross-reactive epitope groups (CREGs).

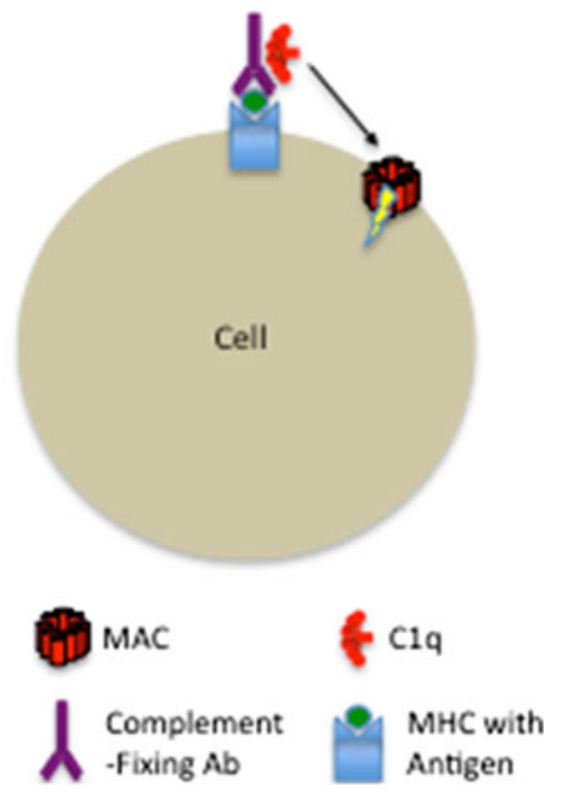

Fig. 2 Complement-activating body. MAC Membrane attack complex, $A b$ antibody
CREGs are shared HLA epitopes through which a single antibody can react to several HLA molecules [7]. Direct CDC only detects class I antibodies on T cells. Purified B cells were required to detect non-class I (probable class II) antibody. The small number of B cells, as well as frequent cell damage caused by the purification process, often led to poor sensitivity [8].

One issue that plagues certain patients is the finding that autoantibodies can cause false positive CDC assays. The finding that a patient's own serum kills the patient's cells in the assay demonstrates the presence of autoantibodies. Specificity improved with this "autocrossmatch" that identified the presence of autoantibodies, but better tests were needed [9]. The addition of DTT (dithiothreitol) serves to reduce and inactivate immunoglobulin $\mathrm{M}$ (IgM) molecules, which are common autoantibodies [10]. Persistence of a positive CDC crossmatch after DTT treatment indicates the crossmatch is not due to autoantibodies of the IgM class.

\section{Antihuman immunoglobulin-enhanced CDC}

False-negative crossmatch rates improved with the development in 1972 of second-generation antihuman immunoglobulin-enhanced CDC (AHG-CDC) assays that detect cytotoxicity-negative and class II antibodies [11-13]. The test result for antibodies may be negative in cytotoxicity assays because they belong to a subclass that poorly activates complement, such as IgG4, or because the antibody titer or target antigen density on the cell is below the minimum threshold required to trigger complement activation. In 
AHG-CDC, antihuman immunoglobulin directed against bound - but non-complement - activating antibody is added to the $\mathrm{CDC}$ assay prior to the addition of complement in order to crosslink larger numbers of molecules, further activating the complement to induce cytotoxic cell death. DNA dye enters the dying cells, as in the direct CDC method and is qualitatively assessed. The more sensitive assays were able to detect low-titer DSAs otherwise missed by direct CDC testing [3].

However, the AHG-CDC method is still dependent on cell death, and consequently interpretation of the results remains subjective. Additionally, confounding antibodies and antigens are a concern. Antibody class identification is neither simultaneous nor quantitative. AHG-CDC assays do not control for non-HLA antibody or autoreactive IgM binding so the falsepositive rate remains high [10]. There is significant methodological variation and added cost, thereby limiting the utility of the AHG-CDC method [14]. Other local modifications are variably used by different centers; these include extended incubation, Amos-modification (washing steps) and crossmatching at $4^{\circ}$ and $37^{\circ}$.

\section{Flow cytometry crossmatch}

The next generation of assays introduced in 1983 utilizes flow cytometry to detect antibodies independent of complement fixation. Three-color Flow cytometry crossmatch (FCXM) consists of adding fluorescent-labeled reagents directed against anti-HLA antibodies as well as T- and B-cell-specific cell surface proteins (CD3 for T-cells and CD19 for B-cells) to cell samples. A sample is run through a flow cytometer to detect anti-HLA antibodies bound to T- and B-cells at the individual cell level. This method can be highly automated and does not require cytotoxicity and cell death, but it is still whole-cell based.

FCXM enables semiquantitative identification of anti-class I and class II antibodies by independently and simultaneously assessing both T and B cells. FCXM offers definitive antibody and class identification at much lower levels than previously obtained. Adding pronase (a predigestion agent) to the assay controls for high nonspecific background due to Fc receptor binding and autoantibodies and improves FCXM sensitivity and specificity [15]. This is especially true for B-cell assays. In one study, a new population of patients who tested positive by FCXM but negative by traditional CDC crossmatch were identified to be at increased risk of rejection [16]. Positivity for DSAs by flow cytometry is associated with in vivo complement fixation, $\mathrm{C} 4 \mathrm{~d}$ deposition and an increased risk of rejection and early graft loss despite a lack of in vitro proof of complement fixing activity [17].

Methodological variation still limits FCXM. Despite its improved sensitivity over direct $\mathrm{CDC}$, between-center variation is an important problem for both the indirect $\mathrm{CDC}$ and
FCXM assays that limits the sharing of data and clinical studies between centers [18]. Pretest factors associated with a donor's medical care can affect test results by changing the number, viability and levels of HLA antigen expression on separated lymphocytes [19]. Even the use of pronase to diminish the impact of nonspecific antibody binding limits FCXM results [20]. FCXM has high false positive rates, making it difficult to determine the clinical relevance and specificity of a positive crossmatch. Antibodies to class II HLA antigens are especially difficult to detect and interpret, particularly if hightiter class I antibodies are detected. Time-consuming and unreliable techniques, such as sera absorption, are often required to confirm that a positive crossmatch was indeed due to a DSA.

\section{Solid-phase assays}

The limitations of the three methods described above led to the development of solid-phase tests using purified HLA molecules to increase specificity. In solid-phase assays, HLA antigens are solubilized, then affixed to a solid matrix in an enzyme-linked immunosorbent assay (ELISA) or to microparticle beads that are analyzed via flow cytometry [21-24]. Bead-based fluorescent assays such as FlowPRA ${ }^{\circledR}$ (One Lambda, Inc., Thermo Fisher Scientific Corp., Canoga Park, CA) use purified antigen affixed to beads to which patient serum is added. AntiHLA antibodies bind to the antigens, and a fluorescent anti-human globulin is added that illuminates when bound to anti-HLA antibodies. FlowPRA ${ }^{\circledR}$ provides a screening test with high sensitivity (FlowPRA Screen ${ }^{\circledR}$ ) and a secondary test with high specificity (FlowPRA Single Antigen $\left.{ }^{\circledR}\right)$. Therefore, a positive screen result may be followed by single antigen identification to determine the specific DSA. The Luminex ${ }^{\circledR}$ assay (Life Technologies, Thermo Fisher Scientific Corp, Carlsbad, CA) provides a high-throughput analysis of samples and has significant clinical utility in risk stratification of patients by evaluating for elevated panel reactive antibody (PRA) and DSA $[25,26]$.

Controlling for non-HLA antibodies and other sources of false-positive results greatly improved specificity [27]. In 2000 Gebel and Bray demonstrated the increasing sensitivity of antibody detection between AHG-CDC methods, solidphase flow cytometry and ELISA [28]. Class II antibody detection greatly improved, and anti-HLA-C antibodies were commonly identified with new reagents that included these antigens. These developments enhanced our ability to clinically interpret these antibodies. Solid-phase assays improved the validity of a clinically relevant positive crossmatch and enabled the transition by the transplant community to organ allocation based on an "in silico" crossmatch, i.e. the virtual crossmatch. This increased the availability of kidneys for 
transplantation in sensitized patients, shortened cold ischemia time and improved healthcare costs [29].

However, solid-phase assays are also not without their limitations. Sensitivity and specificity are still variable. Some anti-HLA antibodies detected on lymphocytes may be undetectable on beads, and antibodies reactive to the beads may not react to lymphocytes. Purifying antigens by removing them from cell membranes can destabilize them, change their conformation, denature them or lead to cryptic (previously hidden) antigen expression [30]. A DSA that is specific for a cryptic antigen may not have any clinical relevance, yet the positive test may prevent a recipient from receiving a perfectly acceptable donor kidney. Microparticle beads have variable antigen density, leading to increased inter- and intra-assay variability. Beads with cross-reactive epitope groups (CREGs) or public epitopes or with multiple alleles for the same antigen lead to dilution of anti-HLA antibodies via cross-reactivity. False-negative results can occur with hightiter DSA due to the prozone effect, which occurs when C1 competitively displaces the detection antibody [31].

Solid-phase assays do not fully control for the confounding effect of IgM antibodies and immune complexes. Latex antibodies, which may be prevalent in children with a history of urologic surgery, may be very difficult to control for as the substrate of the beads includes latex. Laboratory methods are not standardized, limiting between-center comparisons and clinical studies [32].

These tests have a quantitative component, rather than being reported as "present" or "absent". However, the means of quantitation are not standardized, and neither is the result standardized between assays in the same laboratory. There can be marked differences in the quantitation of the same frozen serum sample if performed on different days. Subtle variation in such things as reagent strength or batch-to-batch variability in antigen density on the beads may account for some of the variability in quantification. Laboratories may report the raw mean fluorescence intensity (MFI) of a specific DSA or, to account for some of the aforementioned limiting factors, they may report the MFI divided by (normalized by) the intensity of a negative control bead, or they may report the result as a percentage of a positive control bead. Additional reporting units include standardized fluorescence intensity (SFI), normalized fluorescence intensity ratio (NFIR) or normalization of the MFI to the affinity of the antibody, as well as many others. Consequentially, the clinician must be familiar with the technology and reporting of the local laboratory and be aware that samples tested at different laboratories are not easily comparable. If exact quantitation of the strength of a specific antibody over time is required (e.g. for a clinical trial of a desensitization protocol), then frozen samples of serum from all the time points in question may be assayed at the same time in one "run" using common aliquots of reagents to eliminate inter-assay variability.

\section{Complement-fixing solid-phase assays}

The newest approach to testing is distinguished by its capacity to directly determine the ability of a particular DSA to bind complement. This development promises to be quite important in the clinical setting given that DSAmediated complement fixation via the classical complement pathway is the hallmark of in vivo graft injury. Historic methods of complement fixation detection, the CDC and AHG-CDC assays, are quite limited in terms of both sensitivity and specificity. Flow cytometry-based, wholecell techniques cannot distinguish complement-fixing reactivity among positive antibodies [23].

First-generation complement-activating assays were flow cytometry-based and cell-independent. These assess fluorescent-labeled anti-C4d on the [C4d]FlowPRA ${ }^{\circledR}$ platform, whereby alloantibodies trigger $\mathrm{C} 4$ split product deposition to HLA-coated FlowPRA ${ }^{\circledR}$ beads [33]. Further development utilized direct immunofluorescence with an anti-C4d antibody, resulting in an improvement of assay methodology [34]. Adaptation of C4d-fixing ability to the Luminex ${ }^{\circledR}$ single-antigen bead platform enabled identification of DSA versus non-DSA and complement-fixing ability at the single HLA antigen level [35-37]. Complement-fixing assays were shown to be clinically applicable, as C4d-fixing DSA negatively affected graft and patient survival [37]. However the assay has low sensitivity and the exact clinical significance of the Luminex ${ }^{\circledR}$ C4d SAB is unknown [35]. C4d deposition can occur as the result of non-antibody mediated mechanisms [38]. Ultimately the first-generation complement-fixing assay was found to be not reliable enough for clinical use.

A new complement-fixing assay based on the Luminex ${ }^{\circledR}$ SAB platform utilizes C1q binding. HLA-coated single-antigen Luminex ${ }^{\circledR}$ beads are combined with patient serum and an exogenous source of C1q. Complement-fixing antibody binds the bead-antigen, which then binds C1q. Fluorescent anti-C1q antibody is added, which binds to $\mathrm{C} 1 \mathrm{q}$ and illuminates complement-fixing antibodies (Fig. 3). C1q is the first component of - and therefore is specific for-the classical complement pathway and thus indicates the potential for an antibody to activate complement. C1q assays directly test the complement-binding ability of a particular DSA and are independent of the strength of IgG MFI. The C1q assay has high sensitivity and specificity and has been validated [39]. C1qbinding DSAs are highly correlated to rejection and graft failure in heart and kidney transplant recipients [40-43]. Earlier versions of the commercially available C1q assays had variable performance. More recent (circa 2012) versions from One Lambda include sources of exogenous complement and demonstrate improved reliability.

However, the C1q Luminex ${ }^{\circledR}$ assay has important limitations. It requires high antigen density and high complement/ IgG levels to avoid false negative results. Denatured antigen 


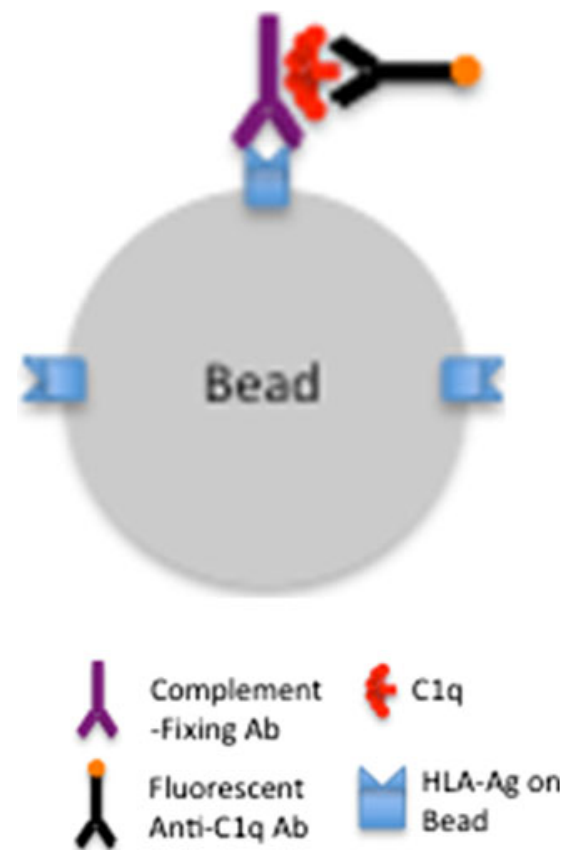

Fig. $3 \mathrm{C} 1$ assay

can lead to decreased bead density and negative $\mathrm{C} 1 \mathrm{q}$ binding. Low complement/IgG levels can also lead to negative C1q binding. Each bead does not have all available alleles for a given antigen. For each method of antibody detection, established techniques, such as adding DTT and/or EDTA and diluting samples, can improve test performance and assess for such factors as IgM autoantibodies and the prozone effect $[10,44]$. While the development of complement-fixing antiHLA testing is exciting and likely of significant clinical importance, small numbers and retrospective study design limit existing studies, and further study is thus warranted.

\section{Clinical implications}

Pre-transplant antibody screening and prospective antibody monitoring identifies the majority of high-risk patients who lose their allograft $[1-3,16,26]$. Patients who develop de novo DSA have decreased graft survival [45]. Complementbinding DSAs are highly associated with decreased graft survival [40-43]. Clinical outcomes have improved dramatically with the advent of antibody detection technology, but the exact clinical relevance of DSA for an individual patient remains uncertain.

\section{Future steps}

Anti-HLA antibody detection and analysis is a rapidly growing aspect of histocompatibility and transplant immunology. Rapid technologic growth has increased our understanding of how DSAs affect pre-transplant immunologic risk and the development of antibody-mediated rejection and graft loss post-transplant. Technologic innovation will continue to improve our ability to define the clinical relevance of anti-HLA antibodies. Molecular analysis of HLA polymorphisms is increasing our understanding of HLA antibodies and their clinical relevance by comparing allele-specific antigen differences [46]. Molecular HLA typing offers intriguing information at the individual patient level into why some DSAs are clinically relevant and others are not. HLA epitope matching may provide a more robust and specific evaluation of immunogenicity [47]. Special consideration must also be given to the costs of existing and future technology, as this may be a limiting factor in the clinical application of the technology [48]. Ultimately these may be problems amenable to the analysis of large datasets, especially if protocols are standardized and reproducible between laboratories.

DSA must be interpreted in the context of the individual patient. A given antibody of moderate titer may have markedly different implications depending on the clinical situation. In a patient who has undergone many sensitizing events and has a history of developing high levels of broad-specificity antibodies, who is known to be noncompliant with medications and who is receiving an extended criteria decreased donor kidney, a moderate level DSA may be ominous. Alternatively, in another patient who has had many sensitizing events without generating significant antibodies, who is highly compliant and who is receiving a living donor kidney, that same antibody may have no clinical importance.

It is vitally important that existing methodologies and protocols be optimized and standardized across laboratories, Organ Sharing Networks and countries. Recent evidence demonstrates the feasibility of standardized protocols, with variability decreased to $20 \%$ [49]. This will lead to greatly reduced inter- and intra-assay variability. Future studies need to optimize study design and can hopefully utilize larger sample sizes with multicenter trials in a prospective manner. Although we have significant experience assessing antibodies pre-transplant, the assessment of antibody status in the post-transplant period is in its infancy. The timing of testing, differentiation of pathogenic and nonpathogenic DSA and optimal responses to changes in antibody titer or development of de novo antibody have yet to be systematically explored. In current clinical practice, it is critically important that the transplant clinician has a collaborative working relationship with the histocompatibility laboratory, with a continuous two-way dialogue to determine how the HLA laboratory can help the clinician and to determine the implications of the laboratory findings. Frequent contact and continual reassessment of methods and policies will improve performance and patient care. 


\section{Key summary points}

1. Donor-specific antibody screening is a critical component of pre- and post-renal transplant management.

2. Direct complement activation underlies the mechanism behind antibody-mediated rejection.

3. Solid-phase assays, independent of whole cells, have improved sensitivity and specificity and enabled evaluation of previously undetectable antibodies.

4. Assays utilizing complement-activating antibodies have improved specificity for clinically relevant antibodies.

5. Methodological variation, lack of standardization and the unknown clinical relevance of a given DSA for an individual patient limit current technology and clinical utility.

Conflict of interest The authors declare that they have no conflict of interest.

\section{Multiple choice questions (answers are provided following the reference list)}

1. HLA class II proteins are expressed almost exclusively on:
a. All nucleated cells
b. Antigen-presenting cells
c. Red blood cells
d. The vascular endothelium

2. Antibody-antigen binding primarily causes cell injury and death by:

a. Activation of the classical complement pathway by binding $\mathrm{Clq}$ and formation of the membrane attack complex (MAC)

b. Activation of the alternative complement pathway

c. Recruitment of natural killer (NK) cells

d. Phagocytosis by neutrophils

3. Limitations of the CDC crossmatch include:
a. Oversaturation of antibodies
b. Background cell death from a critically ill donor
c. DNA dye passively entering healthy cells
d. Neutralizing donor antibodies against complement

4. Strengths of solid-phase assays include all of the following EXCEPT:
a. High-throughput analysis
b. Improved class II antibody detection
c. Controls for non-HLA antibodies
d. Decreased risk of the prozone effect

5. C1q-based solid-phase assays:
a. Directly bind C1q to whole donor cells
b. Rely on recipient sera to provide $\mathrm{C} 1 \mathrm{q}$
c. Are independent of IgG MFI strength
d. Detect C4d deposition on HLA-coated beads

\section{References}

1. Patel R, Terasaki PI (1969) Significance of the positive crossmatch test in kidney transplantation. N Engl J Med 280:735-739

2. Delmonico FL, Fuller A, Cosimi B, Tolkoff-Rubin N, Russell PS, Rodey GE, Fuller TC (1983) New approaches to donor crossmatching and successful transplantation of highly sensitized patients. Transplantation 36:629-633

3. Johnson AH, Rossen RD, Butler WT (1972) Detection of alloantibodies using a sensitive antiglobulin microcytotoxicity test: identification of low levels of pre-formed antibodies in accelerated allograft rejection. Tissue Antigens 2:215-226

4. Ting A, Terasaki P (1975) Lymphocyte-dependent antibody crossmatching for transplant patients. Lancet 305:304-306

5. Neerincx A, Castro W, Guarda G, Kufer TA (2013) NLRC5, at the heart of antigen presentation. Front Immunol 22:397

6. Mittal KK, Mickey MR, Singal DP, Terasaki PI (1968) Serotyping for homotransplantation XVIII. Refinement of microdroplet lymphocyte cytotoxicity test. Transplantation 6:913-927

7. Rodey GE, Neylan JF, Whelchel JD, Revels KW, Bray RA (1994) Epitope specificity of HLA class I alloantibodies I. Frequency analysis of antibodies to private versus public specificities in potential transplant recipients. Hum Immunol 39:272-280

8. Ettenger RB, Terasaki PI, Ting A, Malekzadeh MH, Pennisi AJ, Uittenbogaart C, Garrison R, Fine RN (1976) Anti-B lymphocytotoxins in renal-allograft rejection. N Engl J Med 295: 305-309

9. Ting A, Morris PJ (1977) Renal transplantation and B-cell crossmatches with autoantibodies and alloantibodies. Lancet 310: 1095-1097

10. Barocci S, Valente U, Gusmano R, Perfumo F, Cantarella S, Leprini A, Icardi A, Nocera A (1991) Autoreactive lymphocytotoxic IgM antibodies in highly sensitized dialysis patients waiting for a kidney transplant: identification and clinical relevance. Clin Nephrol 36: $12-20$

11. Gebel HM, Oldfather JW, Karr RW, Fuller TC, Rodey GE (1984) Antibodies directed against HLA-DR gene products exhibit the CYNAP phenomenon. Tissue Antigens 23:135-140

12. Fuller TC, Fuller AA, Golden M, Rodey GE (1997) HLA alloantibodies and the mechanism of the antiglobulin-augmented lymphocytotoxicity procedure. Hum Immunol 56:94-105

13. Fuller TC, Phelan D, Gebel HM, Rodey GE (1982) Antigenic specificity of antibody reactive in the antiglobulin-augmented lymphocytotoxicity test. Transplantation 34:24-29

14. Moore BS, Ploeger NA, DeGoey SR (1997) HLA antibody screening: comparison of a solid phase enzyme-linked immunoassay with antiglobulin-augmented lymphocytotoxicity. Transplantation 64: $1617-1620$

15. Vaidya S, Cooper TY, Avandsalehi J, Barnes T, Brooks K, Hymel P, Noor M, Sellers R, Thomas A, Stewart D, Daller J, Fish JC, Gugliuzza KK, Bray R (2001) Improved flow cytometric detection of HLA alloantibodies using pronase. Transplantation 71:422-428

16. Scornik JC, Clapp W, Patton PR, Van der Werf WJ, Hemming AW, Reed AI, Howard RJ (2001) Outcome of kidney transplants in patients known to be flow cytometry crossmatch positive. Transplantation 71:1098-1102 
17. Karpinski M, Rush D, Jeffery J, Exner M, Regele H, Dancea S, Pochinco D, Birk P, Nickerson P (2001) Flow cytometric crossmatching in primary renal transplant recipients with a negative anti-human globulin enhanced cytotoxicity crossmatch. J Am Soc Nephrol 12:2807-2814

18. Scornik JC, Bray RA, Pollack MS, Cook DJ, Marrari M, Duquesnoy R, Langley JW (1997) Multicenter evaluation of the flow cytometry T-cell crossmatch: results from the American Society of Histocompatibility and Immunogenetics-College of American Pathologists proficiency testing program. Transplantation 63:1440-1445

19. Kuipers HF, Biesta PJ, Groothuis TA, Neefjes JJ, Mommaas AM, van den Elsen PJ (2005) Statins affect cell-surface expression of major histocompatibility complex class II molecules by disrupting cholesterol-containing microdomains. Hum Immunol 66:653-665

20. Hetrick SJ, Schillinger KP, Zachary AA, Jackson AM (2011) Impact of pronase on flow cytometric crossmatch outcome. Hum Immunol 72:330-336

21. Zachary AA, Delaney NL, Lucas DP, Leffell MS (2001) Characterization of HLA class I specific antibodies by ELISA using solubilized antigen targets: I. Evaluation of the GTI QuikID assay and analysis of antibody patterns. Hum Immunol 62:228235

22. Zachary AA, Ratner LE, Graziani JA, Lucas DP, Delaney NL, Leffell MS (2001) Characterization of HLA class I specific antibodies by ELISA using solubilized antigen targets: II clinical relevance. Hum Immunol 62(23):6-246

23. Pei R, Wang G, Tarsitani C, Rojo S, Chen T, Takemura S, Liu A, Lee J (1998) Simultaneous HLA Class I and Class II antibodies screening with flow cytometry. Hum Immunol 59:313-322

24. Kao KJ, Scornik JC, Small SJ (1993) Enzyme-Linked Immunoassay for Anti-HLA antibodies - an alternative to panel studies by lymphocytotoxicity. Transplantation 55:192-196

25. Gibney EM, Cagle LR, Freed B, Warnell SE, Chan L, Wiseman AC (2006) Detection of donor-specific antibodies using HLA-coated microspheres: another tool for kidney transplant risk stratification. Nephrol Dial Transplant 21:2625-2629

26. Caro-Oleas JL, González-Escribano MF, Gentil-Govantes MÁ, Acevedo MJ, González-Roncero FM, Blanco GB, Núñez-Roldán A (2012) Clinical relevance of Anti-HLA donor-specific antibodies detected by Luminex assay in the development of rejection after renal transplantation. Transplantation 94:338-344

27. Braun WE (1991) Donor-specific antibodies. Clinical relevance of antibodies detected in lymphocyte crossmatches. Clin Lab Med 11: 571-602

28. Gebel HM, Bray RA (2000) Sensitization and sensitivity: defining the unsensitized patient. Transplantation 69:1370-1374

29. Bingaman AW, Murphey CL, Palma-Vargas J, Wright F (2008) A virtual crossmatch protocol significantly increases access of highly sensitized patients to decreased donor kidney transplantation. Transplantation 86:1864-1868

30. Gebel HM, Harris SB, Zibari G, Bray RA (2002) Conundrums with FlowPRA beads. Clin Transplant 16:24-29

31. Weinstock C, Schnaidt M (2013) The complement-mediated prozone effect in the Luminex single-antigen bead assay and its impact on HLA antibody determination in patient sera. Int $\mathbf{J}$ Immunogenet 40:171-177

32. Gebel HM, Liwski RS, Bray RA (2013) Technical aspects of HLA antibody testing. Curr Opin Organ Transplant 18(4):455462

33. Wahrmann M, Exner M, Regele H, Derfler K, Körmöczi GF, Lhotta K, Zlabinger GJ, Böhmig GA (2003) Flow cytometry based detection of HLA alloantibody mediated classical complement activation. J Immunol Methods 275:149-160
34. Wahrmann M, Exner M, Haidbauer B, Schillinger M, Regele H, Körmöczi G, Böhmig GA (2005) [C4d]FlowPRA screening - a specific assay for selective detection of complement-activating anti-HLA alloantibodies. Hum Immunol 66:526-534

35. Wahrmann M, Bartel G, Exner M, Regele H, Körmöczi GF, Fischer GF, Böhmig GA (2009) Clinical relevance of preformed C4d-fixing and non-C4d-fixing HLA single antigen reactivity in renal allograft recipients. Transpl Int 22:982-989

36. Zeevi A, Lunz J, Feingold B, Shullo M, Bermudez C, Teuteberg J, Webber S (2013) Persistent strong anti-HLA antibody at high titer is complement binding and associated with increased risk of antibody-mediated rejection in heart transplant recipients. J Heart Lung Transplant 32:98-105

37. Smith JD, Hamour IM, Banner NR, Rose ML (2007) C4d fixing, Luminex binding antibodies - a new tool for prediction of graft failure after heart transplantation. Am J Transplant 7: $2809-2815$

38. Imai N, Nishi S, Alchi B, Ueno M, Fukase S, Arakawa M, Saito K, Takahashi K, Gejyo F (2006) Immunohistochemical evidence of activated lectin pathway in kidney allografts with peritubular capillary C4d deposition. Nephrol Dial Transplant 21:2589-2595

39. Chen G, Sequeira F, Tyan DB (2011) Novel C1q assay reveals a clinically relevant subset of human leukocyte antigen antibodies independent of immunoglobulin $\mathrm{G}$ strength on single antigen beads. Hum Immunol 72:849-858

40. Chin C, Chen G, Sequeria F, Berry G, Siehr S, Bernstein D, Rosenthal D, Reinhartz O, Tyan D (2011) Clinical usefulness of a novel C1q assay to detect immunoglobulin $\mathrm{G}$ antibodies capable of fixing complement in sensitized pediatric heart transplant patients. J Heart Lung Transplant 30:158-163

41. Yabu JM, Higgins JP, Chen G, Sequeira F, Busque S, Tyan DB (2011) C1q-fixing human leukocyte antigen antibodies are specific for predicting transplant glomerulopathy and late graft failure after kidney transplantation. Transplantation 91:342-347

42. Sutherland SM, Chen G, Sequeira FA, Lou CD, Alexander SR, Tyan DB (2012) Complement-fixing donor-specific antibodies identified by a novel C1q assay are associated with allograft loss. Pediatr Transplant 16:12-17

43. Loupy A, Lefaucheur C, Vernerey D, Prugger C, van Huyen JPD, Mooney N, Suberbielle C, Frémeaux-Bacchi V, Méjean A, Desgrandchamps F, Anglicheau D, Nochy D, Charron D, Empana JP, Delahousse M, Legendre C, Glotz D, Hill GS, Zeevi A, Jouven $\mathrm{X}$ (2013) Complement-binding anti-HLA antibodies and kidneyallograft survival. N Engl J Med 369:1215-1226

44. Tambur AR, Herrera ND, Haarberg KMK, Cusick MF, Gordon RA, Leventhal JR, Friedewald JJ, Glotz D (2015) Assessing antibody strength: comparison of MFI, C1q, and titer information. Am J Transplant. doi:10.1111/ajt.1329

45. Wiebe C, Gibson IW, Blydt-Hansen TD, Karpinski M, Ho J, Storsley LJ, Goldberg A, Birk PE, Rush DN, Nickerson PW (2012) Evolution and clinical pathologic correlations of de novo donor-specific HLA antibody post kidney transplant. Am J Transplant 12:1157-1167

46. Tiercy JM, Jeannet M, Mach B (1990) A new approach for the analysis of HLA class II polymorphism: 'HLA oligotyping'. Blood Rev 4:9-15

47. Wiebe C, Pochinco D, Blydt-Hansen TD, Ho J, Birk PE, Karpinski M, Goldberg A, Storsley LJ, Gibson IW, Rush DN, Nickerson PW (2013) Class II HLA epitope matching - a strategy to minimize de novo donor-specific antibody development and improve outcomes. Am J Transplant 13:3114-3122

48. Ziemann M, Schönemann C, Bern C, Lachmann N, Nitschke M, Fricke L, Görg S (2012) Prognostic value and cost-effectiveness of different screening strategies for HLA antibodies prior to kidney transplantation. Clin Transplant 26:644-656 
49. Reed EF, Rao P, Zhang Z, Gebel H, Bray RA, Guleria I, Lunz J, Mohanakumar T, Nickerson P, Tambur AR, Zeevi A, Heeger PS, Gjertson D (2013) Comprehensive assessment and standardization of solid phase multiplex-bead arrays for the detection of antibodies to HLA. Am J Transplant 13:1859-1870

\section{Answers to questions}

1. $b$

2. a

3. b

4. d

5. c 